\title{
Cultural intelligence: Concepts and definition statements
}

\author{
A. Solomon* and R. Steyn \\ School for Business Leadership, University of South Africa \\ *To whom all correspondence should be addressed \\ 78799139@mylife.unisa.ac.za
}

\begin{abstract}
The rapid rate of globalisation is increasingly exposing both individuals and organisations to situations of cultural heterogeneity in which they are expected to function optimally. The cultural intelligence research programme has consequently experienced increased impetus with the result that a broad array of insights now exists. Organising such information will facilitate the assimilation thereof by both business representatives and scholars. Accordingly, this review sought to situate the cultural intelligence literature in terms of the concept and definition statement elements of the general body of scientific knowledge framework. A systematic literature review followed by content analysis was performed. Concepts were crystallised through a fusion of the key words whilst the definition statements were examined to detect elements of both uniqueness and commonality. Despite a large volume of key words existing across the material, remarkably only a limited number of concepts were identified: accomplishment, culture, expatriates, experience, fit, intelligence, motivation, supervision and training. Whilst the definition statements of cultural intelligence have evolved to include, amongst others, its dimensions, the range of culture types it exists in relation to, the categories of persons that may demonstrate it and the conditions in which it could be exhibited, they mostly remain predicated upon the initial expositions.
\end{abstract}

\section{Introduction}

Cultural intelligence (CQ) has been the subject of increasing interest. The principal driver underpinning such focus is globalisation. To this end, Guðmundsdóttir (2015: 175) comments that "globalization has led to a significant increase in cross-cultural interactions". To function effectively in the international arena it is imperative that leaders, managers and staff members alike demonstrate both competence and sensitivity in intercultural dealings as intercultural misunderstandings are common and frequently cause significant impact to the organisation (Earley, 2002). Thomas, Elron, Stahl, Ekelund, Ravlin, Cerdin et al. (2008: 125) state that "the outcome of culturally intelligent behavior is more effective intercultural interaction". Demonstrating culturally intelligent behaviour is therefore vital if individuals and organisations are to overcome the challenges presented by cross-cultural exchanges.

Whilst the research and associated insights on CQ are building, the optimal application of the learnings in commercial activities is being somewhat hampered given the multifaceted and dense lattice of ideas (Blasco, Feldt \& Jakobsen, 2012). An effort to organise such knowledge is therefore called for. Although the authors note the work of Ang, Van Dyne and Rockstuhl (2015) and Bovornusvakool, Ardichvili and Rana (2015) in reviewing the CQ literature they believe additional value could be added by situating it within the concept and definition statement elements of the general body of scientific knowledge framework (see Babbie \& Mouton, 2011), as described herein.

\section{Research purpose and questions}

The purpose of this review was to arrange the literature on CQ according to the concept and definition statement elements of the general body of scientific knowledge framework, through a systematic literature review and subsequent synthesis thereof. Hence, the questions that this study sought to answer were: (a) what are the concepts that are associated with CQ and (b) how is it defined?

\section{Literature review}

The literature review covered two areas. The first addressed the systematic review methodology. The second dealt with the manner in which the valid systematically sourced literature could be organised according to the general body of scientific knowledge framework.

\section{Systematic literature reviews}

A literature review is performed with the aim of gleaning a richer understanding of the nature and meaning of the problem that is being investigated (De Vos, Strydom, Fouche \& Delport, 2013) and is an integral component of most research activities (Nightingale, 2009). Literature reviews may be undertaken for a number of different reasons (Kable, Pich \& Maslin-Prothero, 2012). These include the discovery of up-to-date respected theorising on the subject, to discern the most widely acknowledged empirical observations in the study domain, to detect relevant measures that have demonstrated validity and reliability and to assess established definitions of key concepts pertaining to the subject (Mouton, 2013). In sum, they most often serve to frame the researcher's 
efforts by positioning the topic in a greater knowledge repository (De Vos et al., 2013).

Systematic reviews, which have become increasingly accepted (Kable et al., 2012), were specifically advanced in an attempt to reduce or obviate the researcher's own bias (White \& Schmidt, 2005). As such, they employ overt criteria to locate, source, review and synthesise all the literature on the topic (Cronin, Ryan \& Coughlan, 2008). They make use of an explicit search strategy that is clearly documented and which is targeted at reducing possible prejudice or partiality and random error (Cook, Mulrow \& Haynes, 1997). The purpose of elucidating the respective search methodology is to provide readers with (a) a succinct and unambiguous understanding of the mechanism through which the literature was identified, assessed, evaluated and the outputs thereof and (b) so as to ensure repeatability. Schutte and Steyn (2015: 4) conclude that through the use of "transparent and reproducible procedures, systematic reviews improve the quality and outcome of the review process".

The review of the CQ literature that follows made use of the systematic review methodology. However, without a framework via which to analyse data the possibility exists that the review will be directionless (Rocco \& Plakhotnik, 2009). Consequently, this study sought to organise the literature in terms of the concept and statement (specifically definition) elements of the general body of scientific knowledge framework.

\section{The general body of scientific knowledge framework}

Babbie and Mouton (2011) suggest that research should be situated within the framework of the general body of scientific knowledge. Scientific knowledge is collective in nature and the output of demanding, meticulous and organised enquiry (Babbie \& Mouton, 2011).

De Vos et al. (2013) note that the building blocks of science comprise concepts, statements (definitions, hypotheses and propositions), conceptual frameworks (typologies, models and theories) and paradigms. As this report concentrates on the concepts and definition statements of CQ the discussion that follows is limited to these two elements:

- Concepts - are those words or short phrases that represent an abstract or general idea. Concepts existing in relation to a profession are inexorably a diverse group consisting primarily of notions indigenous to that profession, those borrowed from the underlying sciences and from adjacent vocations (De Vos et al., 2013). Concepts convey meaning through both connotation and denotation (Mouton \& Marais, 1996). Connotation reflects the "subjective attitude or emotion" carried by the concept whilst "objective description" is captured through denotation (Riahi-Belkaoui, 1995: 32). Concepts thus comprise the core ingredients of knowledge. A concept that has been methodically defined for application in scientific theory production depicts a construct (Hox, 1997).
- Definition statements - describe the exact or precise meaning of words or phenomena. As such, they facilitate comprehension in that they ensure common understanding. They exist to demarcate the contextual sense of words (Mouton, 1996), aiding their expression and thereby enriching communication. Definitions may be classified as either (a) constitutive, that is, a concept is defined through the employment of other concepts, terms or words or (b) operational, wherein the procedures that must be adopted in measuring a concept are stated (Ary, Jacobs, Sorenson \& Razavieh, 2010).

\section{Research design and methodology}

In the main, literature review processes comprise 3 distinct components - data collection, data analysis and synthesis (Crossan \& Apaydin, 2010). This study was structured accordingly. Furthermore, a systematic literature review should include (a) the purpose and research question(s) of the review study, (b) the criteria set to determine whether a report will be included or excluded, (c) the procedures by which reports will be identified and sourced and (d) the mechanism through which the included literature will be analysed (Nightingale, 2009; Cronin et al., 2008). In accordance therewith, relevant details of the manner in which the CQ literature was systematically reviewed appear below (noting that the purpose and research questions have been presented above).

\section{Inclusion and exclusion criteria}

The first criterion for inclusion was that of time. Thomas et al. (2008) note that CQ has recently been introduced. Although Earley and Ang first described CQ in 2003 (Ng, Van Dyne \& Ang, 2012; Ang, Van Dyne \& Tan, 2011), Earley (2002) had in fact already made reference to it. Consequently, the commencement date for the systematic search was set at 1 January 2002 with the termination date being 31 May 2015. The termination date was selected so as to represent the present in that the search was conducted primarily during May 2015.

Babbie and Mouton (2011) point out that only data which has been examined and recognised by the scientific community should be incorporated. The second criterion thus required the material to have been published in a peer-reviewed journal in order for it to be included. Badger, Nursten, Williams and Woodward (2000: 227) point out that "being systematic does not mean being all embracing and if exclusion / inclusion criteria are carefully selected then the search can be kept manageable". The third and fourth criteria hence required the studies to be in English and to have CQ (in any format) incorporated into the article, respectively. Where studies were presented in a language other than English or the reference to CQ was, at best, incidental they were eliminated. Identification of the studies 
To boost the likelihood that studies satisfying the inclusion criteria would be located, several databases were examined. These were (a) EBSCO Host Business Source Complete, (b) ProQuest ABI/Inform Global, (c) ProQuest Psychology and (d) SAGE (including archive 1879 onwards). Google Scholar was also scrutinised. As the intention was to identify all relevant studies on CQ no sampling was made use of. The databases were searched for the exact phrase "cultural intelligence". The results from the database searches and Google Scholar were then compared and duplicates eliminated.

In total, 157 unique studies were found across 101 journals. Approximately $71 \%$ (112) of the studies were undertaken in the years 2011 through 2015 indicating the exponential increase in published outputs on CQ and underscoring the timely performance of this study. To satisfy criterion two, all journal titles were compared against Beall's list (see Scholarly Open Access, 2015) in order to identify any that are considered to be potentially, possibly or probably predatory in nature. None of the 101 journal titles were included in Beall's list. Finally, Ulrichsweb (see Serials Solutions, 2015) was searched to validate the journals follow a peer review process. In this regard, 14 of the journals, representing 18 of the identified studies, were found to not practice peer review. The titles of another ten journals were not listed on Ulrichsweb and thus their respective websites were examined to establish compliance with criterion two. The websites of three of these journals did not provide any details on peer review; hence a further three of the identified studies were discarded. The final number of included studies was 136 .

\section{Data analysis and reporting}

As previously indicated, this review analysed the included material according to the concept and definition statement elements of the general body of scientific knowledge framework. Concepts were recognised as the key words listed in the studies. A similar strategy followed by Schutte and Steyn (2015) and Sethibe and Steyn (2015) provided satisfactory results. Definition statements were identified where the studies made use of words such as "define", "describe" or "explain" and associated these directly with CQ. The results of the investigation are reported under findings and are more fully considered in the discussion section that follows thereafter.

\section{Findings}

The findings are separated between concepts and definition statements. Concepts were examined from a connotative perspective whilst constitutive definitions were considered.

\section{Concepts}

Out of the 136 articles, 28 did not present any key words. The 108 remaining articles contained, in total, $515 \mathrm{key}$ words of which 439 were listed just once. Cultural intelligence appeared 96 times whilst the acronym "CQ" was listed three times (99 in total). Cross-cultural adjustment was listed 12 times whilst nine of the articles included emotional intelligence as a key word. Culture, cross-cultural management, cross-cultural training and intelligence appeared seven times. Expatriate and international experience were recorded six times whilst performance was listed five times. Cultural adaptation, expatriates, job performance and self-efficacy appeared four times. Cultural competence, motivation, motivational cultural intelligence, personality, social intelligence and transformational leadership were observed three times. The key words that were listed fewer than three times were mostly attendant variations of those identified above and were thus not directly considered during the process of distilling the concepts.

\section{Definition statements}

In aggregate, 123 studies contained either a definition of CQ or referenced a definition of it through direct quote or paraphrase. As seminal authors in the field of CQ, the definitions provided by P. Christopher Earley and Soon Ang were noted to be those most frequently referenced.

\section{Definitions from Earley (and others, including Ang)}

Earley (2002: 271) defined CQ as “a person's capacity to adapt to new cultural settings". This definition was referenced in one article as a direct quote and was paraphrased in a further three studies. Earley (2002: 274) and Earley and Ang (2003: 59) offered a related definition being "CQ captures a person's capability to adapt effectively to new cultural contexts". This definition was referenced in 22 additional articles (11 each by quote and paraphrase). Chen (2015) highlighted the definition by Earley and Ang (2003: 3) that CQ "is an individual's capability to adapt effectively to situations of cultural diversity". This definition was quoted in a second article whilst the authors of a further 29 studies chose to reference such definition through paraphrasing it. An additional 17 articles rephrased a combination of the two afore-mentioned definitions by Earley and Ang (2003).

Earley and Mosakowski (2004a: 139) collaborated to offer the following definition of CQ: "a seemingly natural ability to interpret someone's unfamiliar and ambiguous gestures in just the way that person's compatriots and colleagues would, even to mirror them". This definition appeared in three additional articles, once as a direct quote and twice through paraphrase. Earley and Mosakowski (2004b: 154) advanced a second description of CQ in terms of which they defined it as "a manager's capability to adjust to new cultures". This definition was not found in any of the other included studies.

Earley and Ang, in conjunction with Tan, (2006: 5), expanded on their previous definition in defining CQ as "a person's capability for successful adaptation to new cultural settings, that is, unfamiliar settings attributable to cultural context". This definition appeared as a direct quote in Groves, Feyerherm and $\mathrm{Gu}$ (2015) and Eken, Özturgut \& Craven (2014) whilst two additional articles paraphrased it. 


\section{Definitions from Ang (and others)}

Ang, Van Dyne, Koh, Ng, Templer, Tay and Chandrasekar (2007: 336) interpreted CQ as "an individual's capability to function and manage effectively in culturally diverse settings". Three of the included studies quoted this interpretation and seven referenced it. A further seven articles (three through direct quote and four via paraphrase), however, ascribed the afore-mentioned description to Ang and Van Dyne (2008). Ang et al. (2007: 336) went on to expand their definition through describing CQ as "a specific form of intelligence focused on capabilities to grasp, reason and behave effectively in situations characterized by cultural diversity".

Ang worked with Inkpen (2008: 338) in proposing that firmlevel CQ is "a form of organizational intelligence or firmlevel capability in functioning effectively in culturally diverse situations". This definition was referred to by paraphrase in one other article.

Van Dyne, Ang and Livermore (2010) presented two expositions of CQ, both of which were referenced through direct quote in Fakhreldin (2011: 3). These definitions are: "one's capability to effectively understand and adapt to a myriad of cultural contexts as an essential skill set needed to lead effectively across cultures" and CQ is "an individual's capability to function effectively across cultures - this can include national, ethnic and organizational as well as other types of culture". This last definition was paraphrased in a second included study.

\section{Definitions from Thomas (and others)}

Thomas and Inkson (2004: 182-183) defined CQ as "a multifaceted competency consisting of cultural knowledge, the practice of mindfulness, and the repertoire of behavioral skills" and was referenced twice by Crowne (2008, 2013). This definition was found as paraphrase in an additional three of the included articles. Thomas and Inkson (2005: 7) later advanced a similar yet more descriptive definition of CQ, that is: "being skilled and flexible about understanding a culture, learning increasingly more about it, and gradually shaping one's thinking to be more sympathetic to the culture and one's behavior to be more fine-tuned and appropriate when interacting with others from the culture". This definition was quoted in one further study.

Through his own work, Thomas (2006: 80), as a single author, defined CQ as "the ability to interact effectively with people who are culturally different". This definition was noted twice amongst the included studies (one article quoted it whilst another paraphrased it).

In association with other scholars, Thomas advanced an alternative definition: "a system of interacting knowledge and skills, linked by cultural metacognition, that allows people to adapt to, select, and shape the cultural aspects of their environment" (Thomas et al., 2008: 126). One article directly quoted this last-mentioned definition whilst a further three referenced it through paraphrase.

A number of other scholars proposed their own definitions of $\mathrm{CQ}$, in particular:

- Brislin, Worthley and MacNab (2006: 53) - CQ "addresses a set of skills, from basic to advanced, that allow an individual to become effective at eventually transferring social skills from one cultural context to another". This definition was recorded as a direct quote in a second article within the study group. An additional study by these authors referred to CQ as "a set of skills and traits that allow one to more effectively interact with novel cultural settings" (MacNab, Brislin \& Worthley, 2012: 1321). This definition was referenced as a direct quote in another of the included studies,

- Creque and Gooden (2011: 143) - CQ is "an individual's cognition or knowledge that influences his perception to a cultural environment or state and which leads to how he behaves in that environment",

- Khodadady and Ghahari (2012: 22) - CQ is "the ability to interact effectively in multiple cultures",

- Lee and Sukoco (2010: 964) - CQ refers to "the ability of each expatriate to adapt effectively across cultures". This definition was included in one other study as a direct quote,

- Lin, Chen and Song (2012: 542) - CQ refers to "the ability to collect and process messages, to make decisions, and the relative approaches needed in order to adjust to a new environment",

- Mansuri (2014: 264) - CQ is "the ability one possesses to adjust and adapt to differences in all aspects, especially culture",

- Moon (2010: 458) - CQ is “an organization's capability to function and manage effectively in culturally diverse environments", and

- Peterson (2004: 89) - CQ is "the ability to engage in a set of behaviors that uses skills (i.e. language or interpersonal skills) and qualities (e.g. tolerance for ambiguity, flexibility) that are tuned appropriately to the culturebased values and attitudes of the people with whom one interacts." This view of CQ was quoted by Crowne (2009) and paraphrased in two of the included articles.

Many of the articles incorporated more than one of the CQ definitions identified above.

\section{Discussion}

The discussion addresses both the concepts and definition statements.

\section{Concepts}

The first research question related to the concepts associated with CQ. Given the quantity of articles included in this study it was not unexpected that a large volume of key words would be identified. As it was CQ being investigated, it was 
anticipated that the majority of the included studies would list "cultural intelligence" or "CQ" as a key word.

To this end, approximately $92 \%$ (99 / 108) of the studies that incorporated key words recorded it as such. This is important in that it validated the focus of the studies as being the direct examination of CQ rather than CQ being addressed purely as a subsidiary consideration.

The following concepts were distilled through a scrutiny of the key words:

- Accomplishment (representing job performance, performance, cultural competence and self-efficacy) culture appropriate and relevant task execution predicated upon self-belief capability,

- Culture (representing culture) - the behaviours, beliefs and customs characteristic of different person groupings,

- Expatriates (representing expatriate and expatriates) persons who are not of or different from the people, place or environment, that is, culturally different or distinct,

- Experience (representing international experience) direct, real and practical involvement in or exposure to cross-cultural events or occurrences,

- Fit (representing cross-cultural adjustment and crosscultural adaptation) - an indication of the extent to which a person combines appropriate, suitable, apt and proper actions and reactions. Fit addresses the extent to which a person is able to acclimate successfully in situations of cultural unfamiliarity and, as such, concerns the inherent emphasis of CQ in that adaptation to a new culture extends beyond the hygiene to a position where outcomes are effective and not merely supplementary,

- Intelligence (representing CQ, emotional intelligence, intelligence, social intelligence and personality) - the facility to realise an objective,

- Motivation (representing motivation and motivational cross-cultural intelligence) - the desire or will to acquire knowledge of other cultures and participate in crosscultural interactions,

- Supervision (representing cross-cultural management and transformational leadership) - direction, coordination or influence of culturally heterogeneous resources in the attainment of specific goals, and

- Training (representing cross-cultural training) - the process or system through which knowledge is delivered and received, including action / experiential learning.

In Figure 1 the key words that were identified are thematically grouped into logical spheres allowing for the portrayal of the above-named concepts. The spheres are shown as (a) overlapping in order to reflect an affiliation between the concepts and (b) in an ascending typology to reveal a process by which CQ might be developed by individuals within a multicultural work environment.

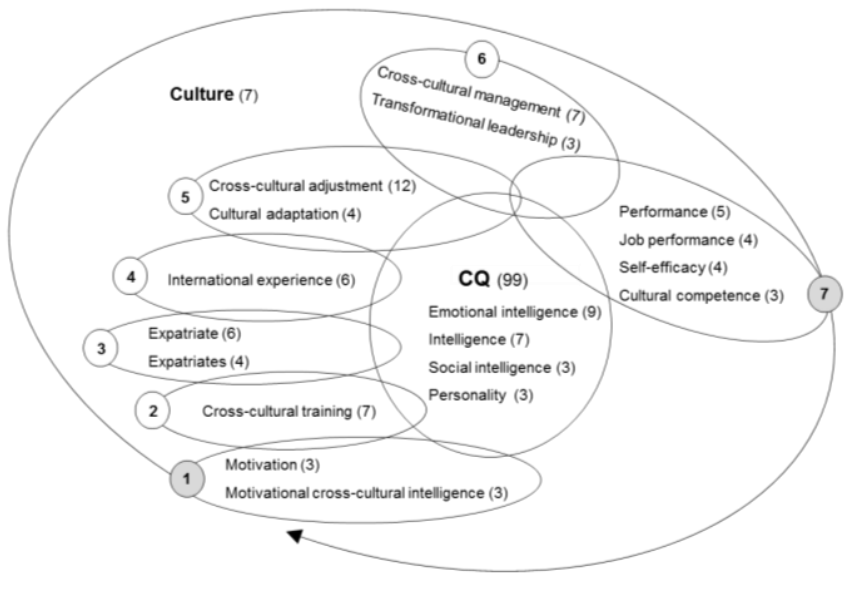

Figure 1: Concepts associated with CQ (figures in brackets represent the number of times the key word appeared)

Per Figure 1, it is submitted that the cultivation of CQ activates with an individual's motivation to pursue intercultural interactions. In preparation therefore, participation in cross-cultural training takes place. The individual enters the foreign culture as an expatriate with his/her CQ further evolving through the accumulation of experience A successful fit within the culture ensues. This fit contributes to adept supervision and fruitful performance delivery.

The above process proposes a possible arrangement of the identified concepts and is thus indicative rather than being based upon empirical evidence. Alternative approaches by which CQ may be boosted are offered by Divyashree (2016) and Van Dyne and Ang (2008).

\section{Definition statements}

The second research question concerned CQ definition statements. In total, 24 definitions were identified amongst the included studies.

The initial, and certainly the most popular, definitions of CQ are those formulated by Earley (2002) and Earley and Ang (2003) which reflect CQ as a person's / individual's capacity / capability to adapt / adapt effectively to new cultural settings / new cultural contexts / situations of cultural diversity. These initial, yet pivotal, definitions appear to be the foundation upon which all subsequent elucidations of CQ are built.

Whereas Earley (2002) and Earley and Ang (2003) initially chose to offer concise definitions of CQ, that is, not directly identify nor reference the CQ dimensions (being metacognitive, cognitive, motivational and behavioural CQ) in their descriptions, other commentators put forward more elaborate explications. To this end, Thomas and Inkson (2005) included what they advocate the three dimensions of CQ to be (that is, knowledge, mindfulness and behaviour) in their definition. It was not until 2007 that Ang, in collaboration with Van Dyne, Koh, Ng, Templer, Tay and Chandrasekar, offered a definition that incorporated the CQ 
dimensions as conceived by Earley and Ang (2003). This definition, though, references the dimensions rather than explicitly naming them per Earley and Ang (2003).

An important observation is that the word "new" in relation to cultural settings or contexts, whilst being included in the definitions of Earley (2002) and Earley and Ang (2003), was omitted from all other definitions apart from those of Lin $e t$ al. (2012), Earley, Ang and Tan (2006) and Earley and Mosakowski (2004b). It is suggested that the reason for this could be that $\mathrm{CQ}$ was originally conceptualised in relation to situations of cultural diversity that the individual had not previously been exposed to. The elimination of "new" from later descriptions might thus serve to draw attention to the role that CQ has to play in all cultural interactions irrespective of whether the individual has formerly been exposed to or operated within such cultural contexts.

Trompenaars and Hampden-Turner (1998: 7) comment that "culture also presents itself on different levels". They indicate that the highest level of culture is that of the nation and point out that culture also exists at the corporate (organisation) and professional levels. It is particularly illuminating then that only the definition of Van Dyne et al. (2010), as quoted by Fakhreldin (2011: 3), highlights the aptitude to function effectively across cultures concerns all levels of culture including "national, ethnic and organizational". The other definitions in describing CQ leave it to the reader to infer that CQ prevails at all cultural levels.

A related observation, gleaned from the definitions, is that CQ references the capability to adjust effectively to many, as opposed to only a single or few, cultures. To stress this Khodadady and Ghahari (2012) and Van Dyne et al. (2010) make use of the words "multiple" and "myriad", respectively.

Wood and St. Peters (2014), Rehg, Gundlach and Grigorian (2012) and Earley and Ang (2003) all point out that CQ can be taught and learnt. With this in mind, the use of "natural" to qualify "ability" in the definition by Earley and Mosakowski (2004a) could be misinterpreted as indicating that CQ is innate, that is, the acquisition and enhancement of CQ is not possible. Rather, it is submitted that Earley and Mosakowski (2004a) are merely emphasising the competence of the culturally intelligent person.

CQ is predominantly defined or described in relation to the individual. Just Ang and Inkpen (2008), and later Moon (2010), offer a description of CQ at the firm or organisational level. Apart from the afore-mentioned definitions, it was solely Van Dyne et al. (2010) who included a reference to the organisation in their definition. However, the reference is to organisational culture as opposed to organisational CQ per se.

Finally, although some of the included studies examined CQ and leadership (including, Eken et al., 2014, Keung \& Rockinson-Szapkiw, 2013 and Ismail, Reza \& Mahdi et al., 2012), it was solely Van Dyne et al. (2010) who described CQ within the context of leading effectively in unfamiliar cultural conditions. Similarly, just the definition by Earley and Mosakowski (2004b) described CQ with specific reference to the manager. Three other definitions did contain the word "manage", however the inclusion appeared to be more directed at the individual managing him / herself in culturally varied situations rather than to the management of subordinates, for example.

It is argued that an integrated definition of CQ should thus cover, at a minimum, those items discussed above. Despite the challenge of improving on the various definitions that have been articulated for CQ, the authors venture that CQ could be described as " $a$ discrete intelligence type, that embraces the ability (which may be enhanced, learned and developed) of individuals and organisations to adjust to and thus function effectively across all types and levels of culture and culturally diverse settings, that they may or may not have previously been exposed to, and which sprouts from the desire to acquire and embodying the capacity to process culture-specific knowledge and is demonstrated through culture appropriate behaviours."

\section{Conclusion}

In this age of amplified intercultural interactions, CQ is attracting ever-increasing attention. To maximise utility from the mounting insights, it is imperative that the business and academic communicates have a clear understanding of it. With the aim of facilitating an improved comprehension, this review has organised the literature in terms of the concepts associated with and the explications used to define CQ.

As integral components of science, concepts and definition statements are essential in laying the groundwork upon which understanding is developed. To this end, the CQ concepts present as a narrow band with particular focus on accomplishment, culture, expatriates, experience, fit, intelligence, motivation, supervision and training. The definition statements have become increasingly descriptive yet continue to centre on the capacity to function effectively in cross-cultural interfaces.

\section{Limitations and recommendations}

This study is subject to four primary limitations. In particular, it is possible that apposite CQ reports may not have been identified. Likewise, applicable insights may have been missed in that they were included in non-published sources only. The CQ dimensions, whilst identified, were not interrogated nor was the denotative meaning of CQ probed.

The connotative meaning of CQ could be further enriched through an exploration of the CQ dimensions whilst examination of the instruments that have been developed to assess it, including pertinent supporting evidence, would contribute to denotative understanding. In addition, the suggested growth of CQ, as illustrated in Figure 1, could be expanded into a conceptual model that is subsequently tested for validity. It is recommended that these research avenues be investigated. 


\section{Contribution}

This study identifies the most common concepts associated with CQ thereby positioning it within the context of inter or cross-cultural activity. It consolidates the many CQ definition statements and in so doing extends the work of Thomas et al. (2008). An analysis of these definition statements is offered and, through a synthesis thereof, an integrated description is suggested. It follows on that the reader should be better positioned to grasp the meaning of CQ.

\section{References}

Ang, S. \& Inkpen, A.C. 2008. 'Cultural intelligence and offshore outsourcing success: A framework of firm-level intercultural capability', Decision Sciences, 39(3): 337-358.

Ang, S. \& Van Dyne, L. 2008. Conceptualization of cultural intelligence: Definition, distinctiveness, and nomological network. In Ang, S. and Van Dyne, L. (Eds.). Handbook of cultural intelligence: Theory, measurement, and application. Armonk: M.E.Sharpe Inc.

Ang, S., Van Dyne, L., Koh, C., Ng, K.Y., Templer, K.J., Tay, C. \& Chandrasekar, N.A. 2007. 'Cultural intelligence: Its measurement and effects on cultural judgment and decision making, cultural adaptation and task performance', Management \& Organization Review, 3(3): 335-371.

Ang, S., Van Dyne, L. \& Rockstuhl, T. 2015, Cultural intelligence: Origins, conceptualization, evolution, and methodological diversity. In Gelfand, M.J., Chiu, C. and Hong, Y. (Eds.). Handbook of advances in culture psychology. New York: Oxford University Press.

Ang, S., Van Dyne, L. \& Tan, M.L. 2011. Cultural intelligence. In Sternberg, R.J. and Kaufman, S.B. (Eds.). Cambridge handbook on intelligence. New York: Cambridge University Press.

Ary, D., Jacobs, L.C., Sorenson, C. \& Razavieh, A. 2010. Introduction to research in education. 8th Edition. Belmont: Wadsworth.

Babbie, E. \& Mouton, J. 2011. The practice of social research. 1st Edition. Cape Town: Oxford University Press Southern Africa.

Badger, D., Nursten, J., Williams, P. \& Woodward, M. 2000. 'Should all literature reviews be systematic?', Evaluation \& Research in Education, 14(3 \& 4): 220-230.

Blasco, M., Feldt, L.E. \& Jakobsen, M. 2012. 'If only cultural chameleons could fly too: A critical discussion of the concept of cultural intelligence', International Journal of Cross Cultural Management, 12(2): 229-245.

Bovornusvakool, W., Ardichvili, A. \& Rana, S. 2015. Cultural intelligence: A review of the literature. Paper presented at the 'UFHRD Conference', 3-5 June, University College Cork, Ireland. Brislin, R., Worthley, R. \& MacNab, B.R. 2006. 'Cultural intelligence: Understanding behaviors that serve people's goals', Group \& Organization Management, 31(1): 40-55.

Chen, A.S. 2015. 'CQ at work and the impact of intercultural training: An empirical test among foreign laborers', International Journal of Intercultural Relations, 47: 101-112.
Cook, D.J., Mulrow, C.D. \& Haynes, R.B. 1997. 'Systematic reviews: Synthesis of best evidence for clinical decisions', Annals of Internal Medicine, 126(5): 376-380.

Creque, C.A. \& Gooden, D.J. 2011. 'Cultural intelligence and global business competencies: A framework for organizational effectiveness in the global marketplace', International Journal of Management and Information Systems, 15(4): 141-146.

Cronin, P., Ryan, F. \& Coughlan, M. 2008. 'Undertaking a literature review: A step-by-step approach', British Journal of Nursing, 17(1): $38-43$.

Crossan, M.M. \& Apaydin, M. 2010. 'A multi-dimensional framework of organizational innovation: A systematic review of the literature', Journal of Management Studies, 47(6): 1154-1191.

Crowne, K.A. 2008. 'What leads to cultural intelligence?', Business Horizons, 51(5): 391-399.

Crowne, K.A. 2009. 'The relationships among social intelligence, emotional intelligence and cultural intelligence', Organization Management Journal, 6(3): 148-163.

Crowne, K.A. 2013. 'Cultural exposure, emotional intelligence, and cultural intelligence: An exploratory study', International Journal of Cross Cultural Management, 13(1): 5-22.

De Vos, A.S., Strydom, H., Fouche, C.B. \& Delport, C.S.L. 2013. Research at grass roots. 4th Edition. Pretoria: Van Schaik.

Divyashree, S. 2016. 'Cultural intelligence in contemporary business organisations', Imperial Journal of Interdisciplinary Research, 2(7):1539-1541.

Earley, P.C. 2002. 'Redefining interactions across cultures and organizations: Moving forward with cultural intelligence', Research in Organizational Behavior, 24: 271-299.

Earley, P.C. \& Ang, S. 2003. Cultural intelligence: Individual interactions across cultures. Palo Alto: Stanford University Press.

Earley, P.C., Ang, S. \& Tan, J. 2006. CQ: Developing cultural intelligence at work. Palo Alto: Stanford University Press.

Earley, P.C. \& Mosakowski, E. 2004a. 'Cultural intelligence', Harvard Business Review, October: 139-146.

Earley, P.C. \& Mosakowski, E. 2004b. 'Toward culture (sic) intelligence: Turning cultural differences into a workplace advantage', Academy of Management Perspectives, 18(3): 151-157.

Eken, I., Özturgut, O. \& Craven, A.E. 2014. 'Leadership styles and cultural intelligence', Journal of Leadership, Accountability and Ethics, 11(3): 154-165.

Fakhreldin, H. 2011. 'The effect of cultural intelligence on employee performance in international hospitality industries: A case from the hotel sector in Egypt', International Journal of Business \& Public Administration, 8(2): 1-18.

Groves, K.S., Feyerherm, A.E. \& Gu, M. 2015. 'Examining cultural intelligence and cross-cultural negotiation effectiveness', Journal of Management Education, 39(2): 209-243. 
Guðmundsdóttir, S. 2015. 'Nordic expatriates in the US: The relationship between cultural intelligence and adjustment', International Journal of Intercultural Relations, 47: 175-186.

Hox, J.J. 1997. From theoretical concept to survey question. In Lyberg, L., Biemer, P., Collins, M., de Leeuw, E., Dippo, C., Schwarz, N. and Trewin, D. (Eds.). Survey measurement and process quality. New York: Wiley.

Ismail, A.M., Reza, R. \& Mahdi, S. 2012. 'Analysis (sic) the relationship between cultural intelligence and transformational leadership', International Journal of Business and Social Science, 3(14): 252-261.

Kable, A.K., Pich, J. \& Maslin-Prothero, S.E. 2012. 'A structured approach to documenting a search strategy for publication: A 12 step guideline for authors', Nurse Education Today, 32(8): 878-886.

Keung, E.K. \& Rockinson-Szapkiw, A.J. 2013. 'The relationship between transformational leadership and cultural intelligence: A study of international school leaders', Journal of Educational Administration, 51(6): 836-854.

Khodadady, E. \& Ghahari, S. 2012. 'Exploring the relationship between foreign language proficiency and cultural intelligence', The International Journal of Language Learning and Applied Linguistics World, 1(1): 22-30.

Lee, L.Y. \& Sukoco, B.M. 2010. 'The effects of cultural intelligence on expatriate performance: The moderating effects of international experience', The International Journal of Human Resource Management, 21(7): 963-981.

Lin, Y., Chen, A.S. \& Song, Y. 2012. 'Does your intelligence help (sic) to survive in a foreign jungle? The effects of cultural intelligence and emotional intelligence on cross-cultural adjustment', International Journal of Intercultural Relations, 36(4): 541-552.

MacNab, B.R., Brislin, R. \& Worthley, R. 2012. 'Experiential cultural intelligence development: Context and individual attributes', The International Journal of Human Resource Management, 23(7): 1320-1341.

Mansuri, L. 2014. 'Exploring reciprocity between cultural intelligence and cross cultural sensitivity', International Journal of Humanities and Social Science, 8(1): 263-266.

Moon, T. 2010. 'Organizational cultural intelligence: Dynamic capability perspective', Group \& Organization Management, 35(4): 456-493.

Mouton, J. 1996. Understanding social research. Pretoria: Van Schaik.

Mouton, J. 2013. How to succeed in your Master's \& Doctoral Studies. 1st Edition. Pretoria: Van Schaik.

Mouton, J. \& Marais, H.C. 1996. Basic concepts in the methodology of the social sciences. 5th Edition. Pretoria: HSRC Publishers.

Ng, K.Y., Van Dyne, L. \& Ang, S. 2012. Cultural intelligence: A review, reflections, and recommendations for future research. In Ryan, A.M., Leong, F.T.L. and Oswald, F.L. (Eds.). Conducting Multinational Research: Applying Organizational Psychology in the Workplace. Washington: American Psychological Association.
Nightingale, A. 2009. 'A guide to systematic literature reviews', Surgery, 27(9): 381-384.

Peterson, B. 2004. Cultural intelligence: A guide to working with people from other cultures. Yarmouth: Intercultural Press.

Rehg, M.T., Gundlach, M.J. \& Grigorian, R.A. 2012. 'Examining the influence of cross-cultural training on cultural intelligence and specific self-efficacy', Cross Cultural Management, 19(2): 215-232.

Riahi-Belkaoui, A. 1995. The cultural shaping of accounting. 1st Edition. Westport: Quorum Books.

Rocco, T.S. \& Plakhotnik, M.S. 2009. 'Literature reviews, conceptual frameworks, and theoretical frameworks: Terms, functions, and distinctions', Human Resource Development Review, 8(1): $120-130$.

Scholarly Open Access. 2015. Beall's List. [online] URL:http://scholarlyoa.com/publishers/

Schutte, F. \& Steyn, R. 2015. 'The scientific building blocks for business coaching: A literature review', SA Journal of Human Resource Management, 13(1): 1-11. http://www.sajhrm.co.za/ index.php/sajhrm/article/view/657/pdf_1

Serials Solutions. 2015. Ulrichsweb Global Serials Directory. [online] http://0-ulrichsweb. serialssolutions.com/login

Sethibe, T.G. \& Steyn, R. 2015. 'The relationship between leadership styles, innovation and organizational performance: A systematic review', South African Journal for Economic and Management Science, 18(3): 325-337.

Thomas, D.C. 2006. 'Domain and development of cultural intelligence: The importance of mindfulness', Group \& Organization Management, 31(1): 78-99.

Thomas, D.C. \& Inkson, K. 2004. Cultural intelligence: People skills for global business. San Francisco: Berrett-Koehler.

Thomas, D.C. \& Inkson, K. 2005. 'Cultural intelligence: People skills for a global workplace', Consulting to Management, 16(1): 59 .

Thomas, D.C., Elron, E., Stahl, G., Ekelund, B.Z., Ravlin, E.C., Cerdin, J., Poelmans, S., Brislin, R., Pekerti, A., Aycan, Z., Maznevski, M., Au, K. \& Lazarova, M.B. 2008. 'Cultural intelligence: Domain and assessment', International Journal of Cross Cultural Management, 8(2): 123-143.

Trompenaars, F. \& Hampden-Turner, C. 1998. Riding the waves of culture: Understanding cultural diversity in business. 2nd Edition. London: Nicholas Brealey Publishing.

Van Dyne, L., Ang, S. \& Livermore, D. 2010. 'Cultural intelligence: A pathway for leading in a rapidly globalizing world'. In Hannum, K.M., McFeeters, B. and Booysen, L. (Eds.). Leadership across differences: Cases and perspectives. San Francisco: Pfeiffer.

White, A. \& Schmidt, K. 2005. 'Systematic literature reviews', Complementary Therapies in Medicine, 13(1): 54-60.

Wood, E.D. \& St Peters, H.Y.Z. 2014. 'Short-term cross-cultural study tours: Impact on cultural intelligence', The International Journal of Human Resource Management, 25(4): 558-570. 